\title{
BMJ Open The Lisbon Cohort of men who have sex with men
}

To cite: Meireles $P$, Lucas $R$, Martins A, et al. The Lisbon Cohort of men who have sex with men. BMJ Open 2015;5: e007220. doi:10.1136/ bmjopen-2014-007220

- Prepublication history and additional material is available. To view please visit the journal (http://dx.doi.org/ 10.1136/bmjopen-2014007220).

Received 15 November 2014 Revised 11 March 2015 Accepted 17 March 2015

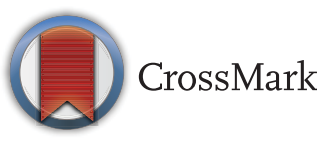

${ }^{1}$ EPIUnit-Institute of Public Health, University of Porto, Porto, Portugal

${ }^{2}$ Department of Clinical Epidemiology, Predictive Medicine and Public Health, University of Porto Medical School, Porto, Portugal

${ }^{3}$ Grupo Português de

Activistas sobre Tratamentos VIH/SIDA (GAT), Lisboa, Portugal

Correspondence to

Paula Meireles;

paula.meireles@ispup.up.pt

\section{ABSTRACT}

Purpose: Newly diagnosed HIV infections among men who have sex with men (MSM) are rising in many European countries. Surveillance tools must be tailored to the current state of the epidemic, and include decentralised prospective monitoring of HIV incidence and behavioural changes in key populations. In this scenario, an open prospective cohort study was assembled-The Lisbon Cohort of MSM-aiming to dynamically monitor the frequency of disease and its predictors.

Participants: The Lisbon Cohort of MSM is an ongoing observational prospective study conducted at a community-based voluntary HIV counselling and testing centre in Lisbon, Portugal (CheckpointLX). Men testing negative for HIV, aged 18 or over and reporting having had sex with men are invited to follow-up visits every 6 months. At each evaluation, a face-to-face interview using a structured questionnaire is conducted, and HIV and syphilis rapid tests are performed by trained peer counsellors. From April 2011 to February 2014, 3106 MSM were eligible to the cohort of whom $923(29.7 \%)$ did not participate. The remaining $2183(70.3 \%)$ MSM were enrolled and 804 had at least one follow-up evaluation, for a total of 893 person-years of observation.

Future plans: The study findings will be disseminated in peer-reviewed journals and presented at national and international conferences. The follow-up of this cohort of HIV-negative MSM will be a valuable tool for monitoring HIV incidence in a setting where limited prospective information existed. Moreover, it will allow for a deeper analytical approach to the study of population time trends and individual changes in risk factors that currently shape the HIV epidemic among MSM.

\section{INTRODUCTION}

Since the beginning of the HIV/AIDS epidemic in the early 80s, gay, bisexual and other men who have sex with men (MSM) have been a core population affected by the disease, but also key contributors to the response to it. $^{1}{ }^{2}$ During the past three decades, significant scientific advances and societal efforts in the fields of prevention,

\section{Strengths and limitations of this study \\ Enables the dynamic monitoring of the frequency of the disease and its predictors. \\ - Enables the comparison of the findings with other cohorts. \\ - Limited representativeness of the sample. \\ - Selection and participation bias. \\ - Possible Hawthorne effect.}

treatment, care and support have renewed the hope of achieving an AIDS-free generation. However, in many high-income countries where a decline in overall HIV diagnoses have been observed, a concurrent increase in the number of new cases among MSM has also been documented. ${ }^{3}$ In the European Union/European Economic Area (EU/EEA) the largest increase in new diagnoses in the last decade was observed among young MSM, aged 20-29 years old. ${ }^{4}$

In Portugal, as in most EU/EEA countries, the HIV epidemic is concentrated in certain key populations, such as MSM, people who inject drugs, prisoners and commercial sex workers. ${ }^{5}$ A large internet survey on Portuguese MSM found a prevalence of selfreported HIV infection of $10.9 \%$ among participants with a previous HIV test. ${ }^{6}$ Although with different methodology, a previous interview survey found a very similar prevalence of $10.3 \%$ of self-reported HIV infection among participants ever tested (Gama A, 2013, personal communication).

Portuguese official surveillance data show a $9 \%$ annual increase in the number of newly diagnosed HIV cases among MSM from 2005 to 2012, while cases due to unsafe injection behaviour and heterosexual intercourse decreased by $18 \%$ and by $2 \%$, respectively, in the same period. ${ }^{7}$ In 2013 , sex between men accounted for $42.9 \%$ of all HIV cases reported in men and $30.3 \%$ of all cases. ${ }^{7}$ Hence, there is an urgency to establish dynamic instruments to monitor HIV 
incidence and determinants in this population if, in fact, we want to succeed in the response to HIV among MSM. ${ }^{1}$

HIV surveillance must be tailored to the state of the epidemic in each setting, and this includes the promotion of decentralised surveillance tools that are capable of capturing HIV trends and behavioural changes in a more timely and analytical fashion than national surveillance systems, which are necessarily heavier structures with a resulting limited applicability for behavioural research. ${ }^{8}$

Community-based studies of MSM present great challenges, namely when it comes to defining a sampling frame, ${ }^{9}$ due to the clear difficulty in establishing the boundaries of the target population itself because of cultural, anthropological and sociological reasons. Traditional sampling strategies designed to ensure representativeness and external validity, such as simple, random or cluster sampling, are often not efficient enough to recruit and follow MSM. ${ }^{8-11}$ Alternative sampling techniques such as convenience sampling in community-based facilities devoted to MSM can be substantially more feasible and improve crucial attributes for the success of integrated epidemiological surveillance such as simplicity, acceptability of participants and stability. ${ }^{8-12}$

The Lisbon Cohort of MSM was assembled as a facilitybased open prospective cohort in a community-based voluntary HIV counselling and testing service directed at MSM. The main objectives of the study are: on a first stage, to quantify the frequency of the disease by estimating the incidence of HIV infection in MSM, and monitoring trends in primary (condom use for anal intercourse (AI)) and secondary prevention (early detection); and, in a subsequent stage, to identify strategies to improve the provision of HIV testing.

\section{Cohort description}

The Lisbon Cohort of MSM is an ongoing observational prospective study established in April 2011, designed as an open cohort. Eligible participants are MSM, aged 18 or older, regardless of nationality or residence, who voluntarily attend CheckpointLX for HIV testing and counselling, and who have a negative HIV test result at the time of recruitment.

\section{Setting}

The cohort is a joint project of GAT Portugal (GAT) and the Institute of Public Health of the University of Porto (ISPUP). GAT is a non-governmental organisation advocating legal and political changes that can have a positive effect on the rights and quality of life of those living with HIV, or those most at risk of acquiring the infection. One of GAT's projects has materialised in CheckpointLX, where the Lisbon Cohort of MSM is recruited. CheckpointLX is a community-based centre for anonymous and free rapid HIV testing and counselling, targeted at MSM, and provided by trained peer
MSM counsellors. ISPUP is an advanced training and research institution in the Public Health domain. With respect to the cohort study, CheckpointLX is responsible for recruitment and data collection, while ISPUP provides scientific support, data management and analysis. Both institutions were involved in the design and implementation of the cohort protocol, and both have established an official partnership to guarantee a shared commitment to the follow-up of cohort participants, and to the periodic dissemination and evaluation of research outputs.

\section{Ethics}

The collected data are confidential, and the participants give their written informed consent prior to inclusion. Furthermore, in accordance with the ethical guidelines for surveillance in populations at higher risk for HIV, the Lisbon Cohort of MSM offers all participants: timely results, information about HIV and AIDS, counselling on HIV prevention and with regard to other health or social needs, linkage to treatment, and care to the extent possible with local resources and protocols with health services for referrals. ${ }^{9}$

\section{Funding}

From April 2011 to March 2014, there was no specific funding for this study. All direct costs with human resources and materials were supported through CheckpointLX as part of its daily activity. Since April 2014, additional specific funding has been obtained as part of the European Commission DG SANCO-Health and Consumers funded Euro HIV EDAT project (grant number 20131101). From inception, ISPUP has provided pro bono contribution through the allocation of research staff time and information technology support (programming, software and hardware) to the project.

\section{Recruitment and follow-up of participants}

Recruitment is generally made on the first visit to CheckpointLX, where peer counsellors invite all eligible individuals to enter the cohort. Eligibility criteria for entering the cohort are being a male aged 18 or over, regardless of nationality or residence, reporting having had sex with other men and having a HIV-negative test result. CheckpointLX is publicised in MSM socialising sites such as bars, discos, saunas, sex shops and guesthouses, parties and events of the gay community, cruising areas and online social networks. The centre itself, since it is located at a Lesbian Gay Bisexual Transgender socialising quarter, promotes walk-ins. Promotional materials include flyers, videos, stickers, banners at online social networks and prevention kits containing condoms, lubricant and an information card about CheckpointLX.

Follow-up is intended to take place at intervals of 6 months, although the exact time between visits is adjusted according to the convenience of the participant. Men who leave their contact details are invited to come back for follow-up visits through text messages or 
email from CheckpointLX staff. All the remaining participants are interviewed and tested for HIV whenever they decide to appear again for testing. Repeat visits are identified by asking if the individual has already been invited to enter the cohort. Most participants do not have trouble remembering if they are part of the cohort. However, if someone does not remember being enrolled in the cohort, the peer counsellor usually gives him some external cues.

End points for follow-up are the acquisition of HIV infection or death. Recruitment began almost 3 years ago; since then, we have followed 804 participants for a total of 893 person-years. Median time between visits was 208 days (approximately 7 months) and 25th-75th centiles were 148-308 days (approximately 5-10 months).

\section{Study procedures \\ Questionnaire}

At each visit, a face-to-face interview is performed by a trained CheckpointLX peer counsellor and data are recorded using a structured questionnaire. The questionnaire applied at cohort entry is divided into the following sections: sociodemographic characteristics, HIV testing history, sexual life and partners, condom use, use of alcohol and drugs, postexposure prophylaxis (PEP) and other sexually transmitted infections (STIs). Follow-up questionnaires update time-varying information on all sections. The questionnaire is provided as an online supplementary file; detailed content is presented in table 1 .

Information is collected from those eligible MSM who decline to participate but agree to provide some baseline data, concerning age, gender, country of origin, educational level, HIV testing history, date and result of previous HIV test, sexual identity, screening for HIV and syphilis at the index visit to CheckpointLX, and reasons for declining participation. Questionnaires are identified through a sequential number, and each participant is identified with a six-digit and four-letter unique code corresponding to their date of birth (YYMMDD), and the first two letters of their first and last names, which allows for data linkage during follow-up while protecting personal identity. ${ }^{9}$ Periodically, questionnaires are sent to ISPUP where they are processed into a computerbased data management system, and where data are stored and analysed.

\section{Rapid HIV testing}

Rapid testing for HIV-1 and HIV-2 is performed at each visit by the same peer counsellor who conducts the interview. From April 2011 to April 2012, two rapid tests were used, namely the Retrocheck HIV (QUALPRO DIAGNOSTICS, Goa, India; manufacturer reported sensitivity $=100.00 \%$ and specificity $=99.75 \%$ ) and Hexagon HIV (Human GmbH, Wiesbaden, Germany; manufacturer reported sensitivity $=100.00 \%$ and specificity $=99.50 \%)$. Since then, only the Alere Determine HIV-1/2 (Alere Medical Co, Ltd, Chiba, Japan; manufacturer reported sensitivity $=100.00 \%$ and specificity $=100.0 \%$, although some studies refer lower specificity ${ }^{13}{ }^{14}$ ) has been used according to the instructions provided by the manufacturer. In case of a reactive test, an outpatient appointment is scheduled for every participant that accepts it at the HIV/Infectious diseases clinic at Santo António dos Capuchos Hospital in Lisbon, where a confirmatory test is performed. The peer counsellor offers to accompany the participant to that appointment. Pretest and post-test counselling is offered at every visit.

\section{Syphilis rapid testing}

Rapid testing for detection of Treponema pallidum antibodies is proposed to every individual who reports with no prior history of syphilis infection or who is unaware of a previous infection; in this instance the Alere Determine Syphilis TP (Alere Medical Co, Ltd, Chiba, Japan; manufacturer reported sensitivity $=92.31 \%$ and specificity $=100.00 \%$ ) is used according to the instructions provided by the manufacturer. In the case of a reactive test, a medical appointment is proposed and scheduled at CheckpointLX as part of the Checklist STI clinic, where a confirmatory test is performed and treatment is prescribed, if needed.

\section{Statistical procedures}

Characteristics of participants at cohort entry were described using absolute and relative frequencies in the case of categorical variables. Medians and percentiles, 25 and 75 (P25-P75), were used to describe continuous variables. Comparisons between groups were performed using the $\chi^{2}$ test or Fisher's exact test when variables were categorical. For continuous variables the Mann-Whitney test was used. In data analysis, all possible answer categories are described, but the missing answers are excluded from the denominator of proportions for each item since no information at all was provided. This is due to the fact that the question was not asked or not recorded in the questionnaire form. The 'rather not say' answers were included in the denominator since they provide valid information reported by the participants.

\section{Characteristics of enrolled population between April 2011 and February 2014}

Between April 2011 and February 2014, there were 3301 potential eligible individuals, 195 (5.9\%) of whom had a HIV reactive test at entry and therefore were not included in the cohort. The remaining 3106 were eligible to the cohort. Among those, 923 (29.7\%) declined to participate, and $2183(70.3 \%)$ were enrolled in the cohort. As of February 2014, 804 of the 2183 participants had been re-evaluated at least once, yielding approximately 2300 questionnaires (figure 1). The most common reasons for declining participation were having no interest in the study (25.7\%), not having the time $(23.5 \%)$ and not living in Portugal (18.0\%). No additional information was collected on this topic. 
Table 1 Content of the questionnaire

1. Sociodemographic characteristics

Date of birth

Gender

Country of birth

Educational level

Employment status

2. HIV testing

Ever tested for HIV

Access to HIV testing result

Reasons for not testing or not having HIV test result

Number of previous HIV tests

Place, date and result of previous HIV test

Reasons for index test

3. Sexual life and partners

Sexual identity

Age at first anal intercourse

Role in anal intercourse

Characteristics of sexual partners in the previous 12 months/since the previous visit*

\section{Entry Follow-up}

A. Steady partner

Steady partner in the previous 12 months/since the previous visit

Duration of the relationship with steady partner

Gender of steady partner

Sexual practices with steady partner

Sexual intercourse with other partners

HIV status of the steady partner

B. Occasional partner

Occasional partner in the previous 12 months/since the previous visit

Number of occasional partners in the previous 12 months/since the previous visit

Sexual practices with an occasional partner

Venues used to meet occasional partners

C. Sex work

Having sex for money or drugs in the previous 12 months/since previous visit

4. Condom use

Condom use with a steady partner in the previous 12 months/since the previous visit

Condom use with a steady partner in the last anal intercourse

Condom use with an occasional partner in the previous 12 months/since the previous visit

Condom use with an occasional partner in the last anal intercourse

Condom use for oral sex

Reasons for not using condom

Lubricant use for anal intercourse

5. Alcohol and drugs

Lifetime use of alcohol or drugs before or during intercourse

Frequency of use of alcohol or drugs before or during intercourse in the previous 12 months/since the previous visit

Perception of reduction in condom use due to use of alcohol or drugs

6. Postexposure prophylaxis

Knowledge of PEP

Lifetime use of PEP

Use of PEP in the previous 12 months/since the previous visit

7. STIs and hepatitis

Lifetime history of STI (symptoms or diagnosis)

Symptoms of STI in the previous 12 months/since the previous visit

Lifetime history of STI diagnosis

Diagnosis of STI in the previous 12 months/since the previous visit

Immunisation status for hepatitis $A$ and hepatitis $B$

Lifetime history of hepatitis virus A, B or C diagnosis

$\begin{array}{ll}\checkmark & - \\ \checkmark & - \\ \checkmark & -\end{array}$

$-$

$-$

$\checkmark$

$-$

$\checkmark \quad-$

$\checkmark-$

$\checkmark \quad-$

$\begin{array}{ll}2 & 2 \\ 2 & 2\end{array}$

$d$

$\checkmark-$

$\begin{array}{ll}2 & 2 \\ 2 & 2\end{array}$

Bisexual men; men with different partners; sex workers; HIV-positive men; injecting drug users; women; trios/group sex.

PEP, postexposure prophylaxis; STI, sexually transmitted infection. 
Figure 1 Flow chart of enrolments between April 2011 and February 2014.

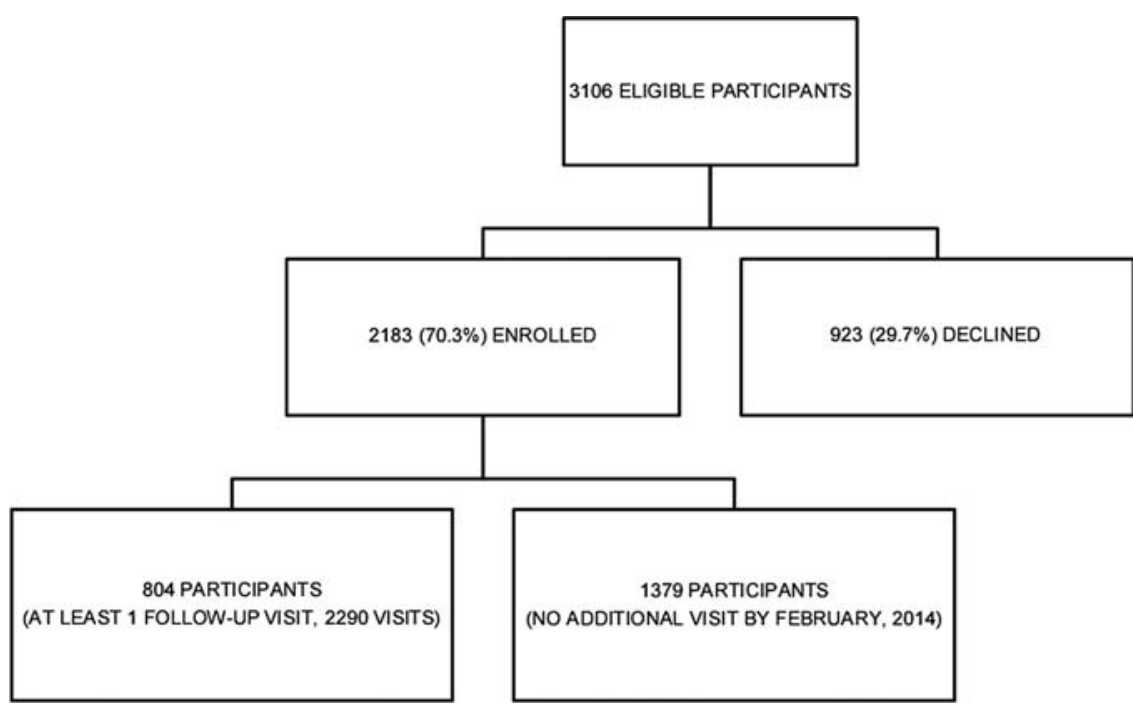

As summarised in table 2, there were significant differences between participants and those who declined to participate: participants self-identified more frequently as homosexual $(83.9 \%$ vs $78.3 \%, \mathrm{p}<0.001)$; participants were more frequently born in Portugal $(75.7 \%$ vs $59.0 \%$, $\mathrm{p}<0.001)$; and $58.1 \%$ of participants had a university degree compared with $51.4 \%$ among those who declined to participate. The proportion of individuals

Table 2 Comparison of sociodemographic characteristics between participants in the cohort and those who declined to participate

\begin{tabular}{|c|c|c|c|}
\hline & $\begin{array}{l}\text { Participants } \\
2183(70.3)\end{array}$ & $\begin{array}{l}\text { Declined to participate } \\
923(29.7)\end{array}$ & p Value \\
\hline Sexual identity, n (\%) & & & $<0.001$ \\
\hline Homosexual & 1831 (83.9) & 709 (78.3) & \\
\hline Bisexual & $306(14.0)$ & $151(16.7)$ & \\
\hline Heterosexual & 28 (1.3) & $37(4.1)$ & \\
\hline Other/did not know/rather not say & $17(0.8)$ & $8(0.9)$ & \\
\hline Missing & 1 & 18 & \\
\hline Age, median (P25-P75) & $29(23-36)$ & $30(24-38)$ & 0.074 \\
\hline Country/region of origin, $n(\%)$ & & & $<0.001$ \\
\hline Portugal & $1573(75.7)$ & $539(59.0)$ & \\
\hline Brazil & $231(11.1)$ & $160(17.5)$ & \\
\hline Other European country & $139(6.7)$ & $141(15.4)$ & \\
\hline African country & 89 (4.3) & $27(3.0)$ & \\
\hline Other American country & $31(1.5)$ & 30 (3.3) & \\
\hline Asia/Middle East/Oceania & $9(0.4)$ & $16(1.8)$ & \\
\hline Rather not say & $5(0.2)$ & $1(0.1)$ & \\
\hline Missing & 106 & 9 & \\
\hline Educational level, n (\%) & & & $<0.001$ \\
\hline Basic education or less & $78(3.6)$ & $101(11.3)$ & \\
\hline Secondary education & $564(25.9)$ & 288 (32.3) & \\
\hline Professional training & $260(11.9)$ & $36(4.0)$ & \\
\hline Bachelor & $896(41.0)$ & $341(38.2)$ & \\
\hline Master or Doctoral & $373(17.1)$ & 118 (13.2) & \\
\hline Other/rather not say & $10(0.5)$ & $9(1.0)$ & \\
\hline Missing & 2 & 30 & \\
\hline Previous HIV testing, n (\%) & & & 0.167 \\
\hline Yes & 1650 (81.9) & $766(83.8)$ & \\
\hline No & $354(17.6)$ & $145(15.9)$ & \\
\hline Did not know & $11(0.5)$ & $2(0.2)$ & \\
\hline Rather not say & $0(0.0)$ & $1(0.1)$ & \\
\hline Missing & 168 & 9 & \\
\hline
\end{tabular}


who had a previous HIV test was similar between groups (81.9\% in participants vs $83.8 \%$ in those who declined to participate).

\section{Characteristics of cohort participants}

Median (P25-P75) number of HIV tests prior to cohort entry was 3 (2-6) and the most common reasons for the index HIV test were: to check health status/routine $(81.3 \%)$, perception of exposure to HIV more than 3 months before $(50.5 \%)$ and within the previous 3 months (40.7\%; table 3$)$.

Table 3 Characteristics related with HIV testing

\begin{tabular}{|c|c|c|}
\hline HIV testing & $\mathbf{N}(\%)$ & Missing \\
\hline Previous HIV testing $(n=2183)$ & & 168 \\
\hline Yes & $1650(81.9)$ & \\
\hline No & 354 (17.6) & \\
\hline Did not know & $11(0.5)$ & \\
\hline Rather not say & $0(0.0)$ & \\
\hline $\begin{array}{l}\text { Number of previous tests, median } \\
\text { (P25-P75) }\end{array}$ & $3(2-6)$ & 31 \\
\hline Place of last HIV test $(n=1650)$ & & 2 \\
\hline $\begin{array}{l}\text { Public network of VCT centres } \\
\text { (CAD) }\end{array}$ & $506(30.7)$ & \\
\hline $\begin{array}{l}\text { Family doctor (National health } \\
\text { service) }\end{array}$ & $311(18.9)$ & \\
\hline $\begin{array}{l}\text { Public hospital (National health } \\
\text { service) }\end{array}$ & $182(11.0)$ & \\
\hline Abroad & $152(9.2)$ & \\
\hline Private laboratory & $150(9.1)$ & \\
\hline Private hospital or clinic & $144(8.7)$ & \\
\hline CheckpointLX & 79 (4.8) & \\
\hline Blood donation & $45(2.7)$ & \\
\hline Mobile unit & $28(1.7)$ & \\
\hline Other & 49 (3.0) & \\
\hline Did not know & $2(0.1)$ & \\
\hline \multicolumn{3}{|l|}{ Reasons for index test $(n=2183)^{*}$} \\
\hline To check health status/routine & $1736(81.3)$ & 49 \\
\hline $\begin{array}{l}\text { Perception of HIV exposure } \\
\text { more than } 3 \text { months before }\end{array}$ & $1084(50.5)$ & 38 \\
\hline $\begin{array}{l}\text { Perception of HIV exposure in } \\
\text { the previous } 3 \text { months }\end{array}$ & $884(40.7)$ & 9 \\
\hline $\begin{array}{l}\text { Accident with condom use } \\
\text { (rupture/left inside) }\end{array}$ & $183(8.6)$ & 56 \\
\hline $\begin{array}{l}\text { My partner asked me to test for } \\
\text { HIV }\end{array}$ & $158(7.4)$ & 57 \\
\hline $\begin{array}{l}\text { To stop using condom with my } \\
\text { partner }\end{array}$ & $149(7.0)$ & 64 \\
\hline $\begin{array}{l}\text { Partner diagnosed HIV } \\
+/ \text { disclosed HIV+ status }\end{array}$ & $138(6.5)$ & 56 \\
\hline $\begin{array}{l}\text { Possible window period by the } \\
\text { time of the last test }\end{array}$ & $136(6.4)$ & 61 \\
\hline Symptoms/medical indication & $58(2.7)$ & 61 \\
\hline Other reason & $159(7.3)$ & \\
\hline
\end{tabular}

*Percentage of participants that answered 'yes' at each option after excluding missing answers. The remaining participants answered no, did not know or rather not say.

CAD, Centro de Aconselhamento e Deteção Precoce do VIH; VCT, voluntary counselling and testing.
Median (P25-P75) age at first AI (receptive or insertive) was 18 (16-22) years, and $1409(65.2 \%)$ men reported having a versatile role on AI, while 553 $(25.6 \%)$ reported having only an insertive role and 177 $(8.2 \%)$ only a receptive role. Twelve per cent reported sexual intercourse with HIV-positive men in the previous 12 months (table 4).

In the previous 12 months, $1373(63.0 \%)$ participants had at least one steady partner, of whom $108(7.9 \%)$ had a HIV-positive partner, $338(24.8 \%)$ were unaware

Table 4 Characteristics related with sexual life and partners

\begin{tabular}{|c|c|c|}
\hline Sexual life and partners & $\mathbf{N}(\%)$ & Missing \\
\hline $\begin{array}{l}\text { Age at first anal intercourse, } \\
\text { median (P25-P75) }\end{array}$ & $18(16-22)$ & 216 \\
\hline Role on anal intercourse & & 22 \\
\hline Only insertive & $553(25.6)$ & \\
\hline Only receptive & 177 (8.2) & \\
\hline Versatile & 1409 (65.2) & \\
\hline Did not know & $2(0.1)$ & \\
\hline Rather not say & $20(1.0)$ & \\
\hline \multicolumn{3}{|c|}{$\begin{array}{l}\text { Intercourse with at least one of the following in the } \\
\text { previous } 12 \text { months }\end{array}$} \\
\hline Bisexual men & & 31 \\
\hline Yes & $732(34.0)$ & \\
\hline No & $1145(53.2)$ & \\
\hline Did not know & 262 (12.2) & \\
\hline Rather not say & $13(0.6)$ & \\
\hline Men with different sex partners & & 32 \\
\hline Yes & $1475(68.6)$ & \\
\hline No & $491(22.8)$ & \\
\hline Did not know & $172(8.0)$ & \\
\hline Rather not say & $13(0.6)$ & \\
\hline Sex workers (even if not paid) & & 32 \\
\hline Yes & $133(6.2)$ & \\
\hline No & 1920 (89.3) & \\
\hline Did not know & $85(4.0)$ & \\
\hline Rather not say & $13(0.6)$ & \\
\hline \multicolumn{3}{|l|}{ HIV-positive men } \\
\hline Yes & $259(12.0)$ & 32 \\
\hline No & $1181(54.9)$ & \\
\hline Did not know & 698 (32.5) & \\
\hline Rather not say & $13(0.6)$ & \\
\hline Injecting drug users & & 32 \\
\hline Yes & $16(0.7)$ & \\
\hline No & $1958(91.0)$ & \\
\hline Did not know & $164(7.6)$ & \\
\hline Rather not say & $13(0.6)$ & \\
\hline Women & & 32 \\
\hline Yes & $287(13.3)$ & \\
\hline No & $1851(86.1)$ & \\
\hline Did not know & $0(0.0)$ & \\
\hline Rather not say & $13(0.6)$ & \\
\hline Trios/group sex & & 33 \\
\hline Yes & $585(27.2)$ & \\
\hline No & $1549(72.0)$ & \\
\hline Did not know & $1(0.0)$ & \\
\hline Rather not say & $15(0.7)$ & \\
\hline
\end{tabular}


Table 5 Characteristics related with steady partners

\begin{tabular}{|c|c|c|}
\hline Steady partner & $\mathbf{N}(\%)$ & Missing \\
\hline Steady partner in the previous & & 2 \\
\hline \multicolumn{3}{|l|}{12 months $(n=2183)$} \\
\hline Yes, one & $1254(57.5)$ & \\
\hline Yes, more than one & $119(5.5)$ & \\
\hline No & $798(36.6)$ & \\
\hline Did not know & $0(0.0)$ & \\
\hline Rather not say & $10(0.5)$ & \\
\hline $\begin{array}{l}\text { HIV status of steady partner } \\
(n=1373)\end{array}$ & & 11 \\
\hline HIV negative & $913(67.0)$ & \\
\hline HIV positive & $108(7.9)$ & \\
\hline Did not know & $338(24.8)$ & \\
\hline Rather not say & $3(0.2)$ & \\
\hline \multicolumn{3}{|l|}{ Condom use with steady partner } \\
\hline $\begin{array}{l}\text { In the last sexual encounter } \\
(n=1373)\end{array}$ & & 70 \\
\hline Yes & $572(43.9)$ & \\
\hline No & $718(55.1)$ & \\
\hline Did not know & $5(0.4)$ & \\
\hline Rather not say & $8(0.6)$ & \\
\hline Frequency in the previous & & 69 \\
\hline \multicolumn{3}{|l|}{12 months $(n=1373)$} \\
\hline Always & $364(27.9)$ & \\
\hline Often/occasionally/rarely/never & $931(71.4)$ & \\
\hline Rather not say & $9(0.7)$ & \\
\hline Frequency in the previous & & 5 \\
\hline \multicolumn{3}{|l|}{$\begin{array}{l}12 \text { months with HIV-positive } \\
\text { steady partner }(n=108)\end{array}$} \\
\hline Always & $57(55.3)$ & \\
\hline Often/occasionally/rarely/never & $45(43.7)$ & \\
\hline Rather not say & $1(1.0)$ & \\
\hline Frequency in the previous & & 10 \\
\hline \multicolumn{3}{|l|}{$\begin{array}{l}12 \text { months with unknown HIV } \\
\text { status steady partner }(n=338)\end{array}$} \\
\hline Always & $95(29.0)$ & \\
\hline Often/occasionally/rarely/never & $233(71.0)$ & \\
\hline Rather not say & $0(0.0)$ & \\
\hline
\end{tabular}

of their steady partner's HIV status and the remaining $913(67.0 \%)$ stated that their steady partner was HIV-negative. More than half of the men who had at least one steady partner reported no condom use with the steady partner in the last sexual encounter (LSE) and approximately $72.0 \%$ reported inconsistent use over the previous 12 months. Among those in a serodiscordant relationship, $43.7 \%$ reported inconsistent use of condoms and that proportion was $71.0 \%$ among those unaware of their steady partner's HIV status (table 5).

Sexual intercourse with at least one occasional partner in the previous 12 months was reported by $1860(85.2 \%)$ participants and the median (P25-P75) number of partners was 4 (2-10). Twenty-one per cent of men who had at least one occasional partner reported no condom use with an occasional partner in the LSE and $46.4 \%$ reported inconsistent use in the previous 12 months. The most referred venues where participants usually met their
Table 6 Characteristics related with occasional partners

Occasional partners
Occasional partners in the
previous 12 months $(\mathrm{n}=2183$ )
Yes
No

Rather not say

Number of occasional partners in the previous 12 months: median N (\%) Missing 0

$1860(85.2)$
$312(14.3)$
$11(0.5)$
$4(2-10)$
45 (P25-P75) $(n=1860)$

Being paid for sex with money or drugs in the previous 12 months $(n=1860)$

Yes

No

$62(3.3)$ $1796(96.6)$

Did not know

$1(0.1)$

\section{Condom use with occasional partner}

In the last sexual encounter

$(\mathrm{n}=1860)$

Yes

$1360(78.3)$

No

$367(21.1)$

$8(0.5)$

Did not know

$1(0.1)$

Rather not say

Frequency in the previous

12 months $(n=1860)$

Always

925 (53.3)

Often/occasionally/rarely/never

$806(46.4)$

Did not know

$2(0.1)$

Rather not say

$4(0.2)$

Venues used to meet occasional partners $(n=1860)^{*}$

Internet

Discos and gay bars

$1338(72.2) \quad 8$

Cruising sites

$897(48.4) \quad 7$

$430(23.2) \quad 10$

Saunas

$356(19.3) \quad 11$

Gym

'Dark rooms' (including sex

$232(12.6) \quad 14$

$129(7.0) \quad 11$

shops)

Sex clubs

$92(5.0) \quad 10$

Other

$445(23.9)$

*Percentage of participants that answered 'yes' at each option after excluding missing answers. The remaining participants answered no, did not know or rather not say.

occasional partners were the internet $(72.2 \%)$, discos and gay bars (48.4\%), and cruising sites (23.2\%; table 6).

Condoms were always used for oral sex by $2.3 \%$ of participants. Always using condoms for AI in lifetime was reported by $652(32.9 \%)$ participants. Among the 1318 $(66.5 \%)$ participants who reported not having always used condoms for $\mathrm{AI}$, the most common reasons for engaging in unprotected AI were a steady partner (66.2\%), a steady partner after testing negative for HIV (47.9\%), 'reliable' persons $(39.8 \%)$ and being too aroused $(37.1 \%$; table 7$)$.

Lifetime use of alcohol (regardless of the amount) or drugs before or during intercourse was reported by 1520 $(69.7 \%)$ participants, and $1262(59.5 \%)$ reported consumption in the previous 12 months. The most frequently 
Table 7 Characteristics related with condom use

\begin{tabular}{|c|c|c|}
\hline Condoms & $\mathbf{N}(\%)$ & Missing \\
\hline Lifetime condom use on oral sex $(n=2183)$ & & 7 \\
\hline Always & $49(2.3)$ & \\
\hline Often/occasionally/rarely/never & $2106(96.8)$ & \\
\hline Rather not say & $21(1.0)$ & \\
\hline Lifetime condom use on anal intercourse $(n=2183)$ & & 202 \\
\hline Always & $652(32.9)$ & \\
\hline Often/occasionally/rarely/never & $1318(66.5)$ & \\
\hline Rather not say & $11(0.6)$ & \\
\hline \multicolumn{3}{|l|}{ Reasons for not using condom on anal intercourse $(n=1318)^{\star}$} \\
\hline With steady partner & $870(66.2)$ & 3 \\
\hline With steady partner after testing for HIV and both were negative & $629(47.9)$ & 5 \\
\hline With a 'reliable' person & $523(39.8)$ & 3 \\
\hline Being too aroused & $487(37.1)$ & 6 \\
\hline Condom reduces pleasure & $360(27.4)$ & 5 \\
\hline With a partner who declares he is HIV negative & $303(23.1)$ & 7 \\
\hline Not having condoms at that moment & 261 (19.9) & 5 \\
\hline If the participant has used alcohol or drugs & $226(17.2)$ & 5 \\
\hline Condom interrupts sexual intercourse & $201(15.3)$ & 5 \\
\hline Does not like using condoms & $205(15.6)$ & 5 \\
\hline Condom makes the participant lose erection & $188(14.3)$ & 4 \\
\hline With a partner who does not want to use & $124(9.4)$ & 5 \\
\hline Being in a sex venue without condoms available & $59(4.5)$ & 6 \\
\hline Condoms are expensive & $40(3.0)$ & 6 \\
\hline With a partner who declares undetectable viral load $†$ & $19(9.5)$ & 5 \\
\hline Allergy to latex & $24(1.8)$ & 6 \\
\hline Other reasons & $77(5.8)$ & - \\
\hline
\end{tabular}

reported psychoactive substances were alcohol (57.6\%), poppers $(17.8 \%)$ and cannabis $(15.9 \%$; table 8$)$.

A little over one-third of participants had heard about PEP, and 54 participants $(2.7 \%)$ knew about and had used PEP (table 9).

A lifetime history of STI symptoms or diagnoses was reported by $37.1 \%$ of respondents; and $9.9 \%$ reported STI symptoms/diagnoses in the past 12 months. The most commonly reported STI in the past 12 months was gonorrhoea $(2.5 \%)$, followed by syphilis $(1.7 \%)$. In total, $0.5 \%$ of respondents reported a lifetime history of hepatitis $\mathrm{C}$ diagnosis (none of whom reported injection drug use; table 10).

\section{STRENGTHS AND LIMITATIONS}

The Lisbon Cohort of MSM is the first Portuguese prospective study of MSM in the context of HIV incidence and testing. As an open prospective study, it will provide information on the trends of HIV infection and other STIs among MSM in Portugal, and it will contribute to identify and monitor determinants of infection, including risk-taking behaviours.

Until recently, serological and behavioural evidence relating to HIV among MSM in Portugal was scarce, apart from the necessarily succinct indicators obtained through routine national HIV surveillance. Two recent cross-sectional studies ${ }^{15} 16$ targeting MSM in Portugal provided the first population-based estimates of selfreported prevalence among MSM with a previous HIV test: $10.9 \%^{6}$ and $10.3 \%$ (Gama A, 2013, personal communication). In addition to these alarming estimates, both studies have raised important concerns regarding the future of the epidemic in Portugal supporting the need for closer monitoring of behavioural and serological indicators within a dynamic framework.

A few cohorts follow HIV-negative MSM internationally with different recruitment strategies and settings. For instance, the Amsterdam Cohort Studies (ACS) on HIV infection and AIDS, which started shortly after the first cases of AIDS had been diagnosed in the Netherlands, ${ }^{17}$ and the Multicenter AIDS Cohort Study (MACS), initiated in 1983 in four universities in the USA $;{ }^{18}$ both are based at formal health or academic facilities. The Omega Cohort Study in Montreal, Canada, was carried out from October 1996 to July 2003 at formal health facilities and at community organisations. ${ }^{19}$ The Health in Men (HIM) in Sydney, Australia, was established in July $2001^{20}$ and, recently, in 2008, The ITACA cohortHIV negative MSM cohort study for early diagnosis of HIV and other STIs and their determinants was established in Barcelona. Both of these are community-based open cohorts. ${ }^{21}$ These cohorts have significantly contributed to our understanding of the HIV/AIDS epidemic, 
Table 8 Characteristics related with alcohol and drug use before or during intercourse

\begin{tabular}{|c|c|c|}
\hline Alcohol and drugs & N (\%) & Missing \\
\hline $\begin{array}{l}\text { Lifetime use of alcohol or drugs } \\
\text { before or during intercourse } \\
(n=2183)\end{array}$ & & 1 \\
\hline Yes & $1520(69.7)$ & \\
\hline No & 662 (30.3) & \\
\hline $\begin{array}{l}\text { Use of alcohol or drugs before or } \\
\text { during intercourse in the previous } \\
12 \text { months }(n=2183)\end{array}$ & & 62 \\
\hline Yes & $1262(59.5)$ & \\
\hline No & 837 (39.4) & \\
\hline Did not know & $4(0.2)$ & \\
\hline Rather not say & $19(0.9)$ & \\
\hline \multicolumn{3}{|c|}{$\begin{array}{l}\text { Ever used alcohol or drugs before or during intercourse in } \\
\text { the previous } 12 \text { months }(n=2183)^{*}\end{array}$} \\
\hline Alcohol & $1256(57.6)$ & 4 \\
\hline Poppers & 389 (17.8) & 2 \\
\hline Cannabis & 329 (15.9) & 114 \\
\hline Cocaine & $236(10.8)$ & 1 \\
\hline Ecstasy & $123(5.6)$ & 3 \\
\hline Viagra/cialis/similar & $89(4.1)$ & 2 \\
\hline Mephedrone & $76(3.5)$ & 3 \\
\hline Amphetamines & 72 (3.3) & 3 \\
\hline $\mathrm{GHB}$ & $37(1.7)$ & 2 \\
\hline Ketamine & $32(1.5)$ & 2 \\
\hline LSD & $31(1.4)$ & 3 \\
\hline Heroin & $7(0.3)$ & 3 \\
\hline Methadone & $8(0.4)$ & 2 \\
\hline Others & 49 (2.2) & - \\
\hline
\end{tabular}

*Percentage of participants that answered 'yes' at each option after excluding missing answers. The remaining participants answered no, did not know or rather not say.

GHB, gamma-hydroxybutyric acid; LSD, lysergic acid diethylamide.

and the HIM and ITACA cohorts, especially, will enable comparisons of their findings with those of our newly developed infrastructure. Additionally, the Lisbon Cohort of MSM has the potential to serve as a modern decentralised surveillance structure that will provide dynamic information about the frequency of the disease and its determinants in this group. Within our geographical setting, this study has the potential to enable locally adapted responses in terms of service provision, namely on the development of effective strategies to anticipate diagnosis. The cohort will also allow for comparisons of behavioural indicators drawn from entry and follow-up questionnaires within the international

Table 9 Characteristics related with PEP

\begin{tabular}{lcl}
\hline PEP (n=2183) & N (\%) & Missing \\
\hline Did not know about PEP & $1228(61.2)$ & 175 \\
Knows but never used & $726(36.2)$ & \\
Knows and used & $54(2.7)$ & \\
\hline PEP, postexposure prophylaxis. & &
\end{tabular}

context, since it collects the set of indicators for behavioural surveillance among MSM defined by the European Centre for Disease Control and Prevention (ECDC). ${ }^{22}$ Finally, a set of specific analytical research objectives will be pursued, with strong emphasis on how contextual and behavioural trajectories throughout follow-up may be used to predict the risk of seroconversion.

The Lisbon Cohort of MSM has a relevant strength in the peer-based approach provided by CheckpointLX. Peer-based services attempt to promote an adequate response to MSM needs, to be non-judgemental and inclusive, which has been reported as the preference of gay and other MSM for testing services. ${ }^{23}$ From a research point of view, we believe this approach can also help in reducing social desirability bias with regard to the information collected, and can be more costeffective than interventions based on clinical staff. ${ }^{24}$ Another strength of the cohort is the assurance of anonymity, which is expected to influence completeness of reporting and disclosure of risk. ${ }^{9}$ Furthermore, CheckpointLX peer counsellors accompany newly identified HIV-positive participants to their first appointment at a HIV/Infectious disease clinic to boost linkage to care. This strategy is in common with that of other community-based centres dedicated to MSM in European countries that have shown to have high efficiency in HIV detection and linkage to care. ${ }^{25} 26$

The Lisbon Cohort of MSM, as a facility-based structure, is unlikely to result in a representative sample of the source MSM population, which limits the generalisability of our findings to the whole community. This is a frequent concern in studies with non-probabilistic samples, but it should not be used as an argument for not attempting to generate the best scientific evidence possible within real-world constraints. In addition, by following only MSM who actively seek HIV testing, we are arguably selecting a subgroup that might be on average at a higher risk of infection than the general MSM community. Consequently, this focuses our attention onto a priority subset of the population (even if potentially more aware than those not reached by the service). The following comparisons are useful to assess the extent of selection bias (table 11). In the 2007 National Health and Sexuality Survey (HSS), ${ }^{27}$ which included a representative sample of the Portuguese population, $4.7 \%$ of adult male individuals reported some kind of sexual contact with other men in their lifetime, $3.0 \%$ of sexually active men had sex with men in the previous 12 months, and $0.9 \%$ reported homosexual identity. Despite the heteronormative frame still persistent in Portuguese society, ${ }^{27}$ the proportion of men reporting sex with other men is quite similar to that estimated by Marcus et al, where approximately $3.0 \%$ of the adult male population living in Portugal were estimated to be MSM. ${ }^{28}$ Men in our sample are clearly younger than in the HSS, where about $31 \%$ were less than 25 years old, whereas men who have had some kind of sexual contact 
Table 10 Characteristics related with STIs

STIs and hepatitis

N (\%)

Missing

Yes, in the previous 12 months

Yes, more than 12 months before No

STI diagnosed ( $n=2183)$

History of gonorrhoea

Yes, in the previous 12 months

Yes, more than 12 months before

No

Did not know

History of syphilis

Yes, in the previous 12 months

Yes, more than 12 months before

No

Did not know

History of condyloma or genital warts

Yes, in the previous 12 months

Yes, more than 12 months before

No

Did not know

History of chlamydia

Yes, in the previous 12 months

Yes, more than 12 months before

No

Did not know

History of genital herpes

Yes, in the previous 12 months

Yes, more than 12 months before

No

Did not know

History of Trichomonas

Yes, in the previous 12 months

Yes, more than 12 months before

No

Did not know

History of lymphogranuloma venereum

Yes, in the previous 12 months

Yes, more than 12 months before

No

Did not know

Lifetime history of hepatitis diagnosis $(n=2183)$

History of hepatitis A

Yes

No

Did not know

Rather not say

History of hepatitis B

Yes

No

Did not know

Rather not say

History of hepatitis C

Yes

No

Did not know

Rather not say

Vaccination $(n=2183)$

Hepatitis A

Yes

No

Did not know

Rather not say

Hepatitis B

Yes

No

Did not know

Rather not say
$216(9.9)$

$593(27.2)$

$1368(62.8)$

57 (2.5)

$169(7.8)$

1946 (89.3)

8 (0.4)

$38(1.7)$

$116(5.3)$

2026 (92.9)

$2(0.1)$

68 (3.1)

$22(1.0)$

$2088(95.6)$

$2(0.1)$

$64(2.9)$

$14(0.6)$

$2096(96.1)$

7 (0.3)

$4(0.2)$

$21(1.0)$

$2(0.1)$

$3(0.1)$

$1(0.0)$

$2176(99.7)$

$2(0.1)$

$0(0.0)$

$2(0.1)$

$2178(99.8)$

$2(0.1)$

127 (5.8)

$1897(87.4)$

$137(6.3)$

$10(0.5)$

$52(2.4)$

$2002(92.3)$

$106(4.9)$

$10(0.5)$

$10(0.5)$

2032 (93.7)

$116(5.4)$

$10(0.5)$

827 (38.0)

742 (34.1)

596 (27.4)

$10(0.5)$

1603 (73.6)

312 (14.3)

252 (11.6)

$10(0.5)$
2153 (98.8) 
Table 11 Comparison of the Lisbon Cohort of MSM with previous studies in Portugal

\begin{tabular}{llll}
\hline & Lisbon Cohort of MSM & HSS* & EMIS Portugal† \\
\hline Age & & & Not available \\
Median (P25-P75) & $29(23-36)$ & 9.8 & $32(25-40)$ \\
Up to 24 (\%) & 30.9 & Not available & 28.0 \\
University degree (\%) & 58.1 & 35.9 & 61.9 \\
Self-reported homosexual identity (\%) & 83.9 & 61.0 & 73.6 \\
HIV previous test (\%) & 81.9 & Not available & 77.0 \\
Lifetime use of PEP (\%) & 2.7 & & 2.1 \\
\hline
\end{tabular}

*Between only those men who have had some kind of sexual contact with men.

tSubanalysis of participants aged 18 years or more living in the Lisbon region.

EMIS, European men who have sex with men internet survey; HSS, Health and Sexuality Survey; MSM, men who have sex with men; PEP, postexposure prophylaxis.

with men in that age strata represent only $9.8 \%$ in the HSS. Men in the Lisbon Cohort reported more frequently of having had a previous HIV test $(81.9 \%$ vs $61.0 \%$ in HSS). When compared with the European MSM internet survey results ${ }^{15}$ from a subanalysis including only participants aged 18 or more living in the Lisbon region, men in our sample have lower median age (29 vs 32) and lower educational level $(58.1 \%$ with an university degree vs $61.9 \%$ ), but report homosexual identity more frequently $(83.9 \%$ vs $73.6 \%)$, previous HIV test $(81.9 \%$ vs $77.0 \%)$ and lifetime use of PEP (2.7\% vs $2.1 \%)$.

We may assume that we are capturing men who are more self-identified as homosexual, which was expected once CheckpointLX was targeted to this group, and perhaps more aware of HIV risk as the frequency of uptake of HIV testing is higher than in the previous studies. It is important to stress that since CheckpointLX promotion strategies remained similar during follow-up, we do not expect a change in the extent of selection bias over time, which is particularly important for the estimation of secular trends of infection and behaviours in the source population..$^{8-10}$

Participation bias is also a key methodological issue in epidemiological studies. In fact, participants in our study are more self-identified as homosexual, more frequently born in Portugal and more educated than those who declined to participate. This implies that important data may be missing on a harder to reach subset of the target population. However, it is interesting to note that the proportion of a previous HIV test is similar between groups, suggesting that both groups may have similar perceived high risk of acquiring HIV. ${ }^{29} 30$

Attrition is a main concern in prospective investigations; due to the fact that this is not an interval cohort with fixed follow-up times, the ability to estimate attrition in a short time frame is limited. However, efforts have been made in order to minimise dropout rates. CheckpointLX peer counsellors ask all participants to provide their email or mobile phone contact details on their first visit and to update their contact details in the follow-up assessments. These details are then used, with the consent of the participants, in order to send reminders within the month of an intended follow-up.

One other ongoing challenge is the possible behavioural modification by cohort participants due to their participation in an investigation, known as the Hawthorne effect. This aspect also relates to the dual role of CheckpointLX as a healthcare/counselling provider and research structure. Checkpoint's first priority is that appropriate and high-quality pretest and post-test information or counselling is offered, and hopefully that will produce a change towards better health empowerment, likely to influence the risk of the outcomes being studied. ${ }^{31}$

\section{COLLABORATION}

We invite scientists, researchers and students from graduation or postgraduation to get involved in data collection and/or analyses, and to raise new scientific questions in the scope of the Lisbon Cohort of MSM. Requests for data analysis, presentation or publication, must be submitted to the Lisbon Cohort of MSM scientific coordination, and will require acknowledgement that Lisbon Cohort of MSM has the property of the data. Information is available at http://www.checkpointLX.com.

Acknowledgements The Lisbon Cohort of MSM team thanks all participants; thanks the CheckpointLX team of peer counsellors-Fernando Ferreira, Hugo Machado, Jesus Rojas, Julio Esteves Miguel Rocha and Nuno Pinto; and also thanks Dina Cosme from ISPUP.

Contributors PM drafted the manuscript and performed the descriptive data analysis. RL participated in the study design, helped draft the manuscript, participated in analysis and interpretation of data, and reviewed the manuscript for important intellectual content. AM participated in analysis and interpretation of data, and reviewed the manuscript for important intellectual content. ACC reviewed the manuscript for important intellectual content. RF and JB participated in the study design and data collection, and reviewed the manuscript for important intellectual content. MJC, LM and HB conceived the study, participated in the study design and coordination, and reviewed the manuscript for important intellectual content.

Funding From April 2011 to March 2014, this specific research has received no funding; all direct costs with human resources and materials were supported by CheckpointLX, as part of its regular activity. Research staff time and information technology support were provided pro bono by ISPUP. Since 
April 2014, after the period of data collection reported in this article an additional specific funding has been obtained as part of the European Commission DG SANCO-Health and Consumers funded Euro HIV EDAT project (grant number 20131101)

Competing interests None.

Ethics approval Ethics Committee of São João Hospital and Medical School, University of Porto (ID 104/12).

Provenance and peer review Not commissioned; externally peer reviewed.

Data sharing statement No additional data are available.

Open Access This is an Open Access article distributed in accordance with the Creative Commons Attribution Non Commercial (CC BY-NC 4.0) license, which permits others to distribute, remix, adapt, build upon this work noncommercially, and license their derivative works on different terms, provided the original work is properly cited and the use is non-commercial. See: http:// creativecommons.org/licenses/by-nc/4.0/

\section{REFERENCES}

1. Beyrer C, Sullivan PS, Sanchez J, et al. A call to action for comprehensive HIV services for men who have sex with men. Lancet 2012;380:424-38.

2. Killen J, Harrington M, Fauci AS. MSM, AIDS research activism, and HAART. Lancet 2012;380:314-16.

3. Beyrer C, Baral SD, van Griensven F, et al. Global epidemiology of HIV infection in men who have sex with men. Lancet 2012;380:367-77.

4. Janiec J, Haar K, Spiteri G, et al. Surveillance of human immunodeficiency virus suggests that younger men who have sex with men are at higher risk of infection, European Union, 2003 to 2012. Euro Surveill 2013;18:20644.

5. Joint United Nations Programme on HIV/AIDS (UNAIDS), Comunidade dos Países de Língua Portuguesa/Community of Portuguese Language Speaking Countries (CPLP). Epidemia de VIH nos países de língua oficial portuguesa: Situação atual e perspectivas futuras rumo ao acesso universal à prevenção, tratamento e cuidados, 2010.

6. Marcus U, Hickson F, Weatherburn P, et al. The EMIS network. Prevalence of HIV among MSM in Europe: comparison of self-reported diagnoses from a large scale internet survey and existing national estimates. BMC Public Health 2012;12:978.

7. Departamento de Doenças Infecciosas. Unidade de Referência e Vigilância Epidemiológica. Núcleo de Vigilância Laboratorial de Doenças Infecciosas; colab. Programa Nacional para a Infeção VIH/ SIDA. Infeção VIH/SIDA: a situação em Portugal a 31 de dezembro de 2013. Lisboa: INSA, 2014.

8. World Health Organization/Joint United Nations Programme on HIV/ AIDS (WHO/UNAIDS). Second generation surveillance for HIV: The next decade, 2000

9. World Health Organization/Joint United Nations Programme on HIV/ AIDS (WHO/UNAIDS). Guidelines on surveillance among populations most at risk for HIV. Switzerland, 2011.

10. Paquette D, De Wit J. Sampling methods used in developed countries for behavioural surveillance among men who have sex with men. AIDS Behav 2010;14:1252-64.

11. Magnani R, Sabin K, Saidel T, et al. Review of sampling hard-to-reach and hidden populations for HIV surveillance. AIDS 2005;19:S67-72

12. German RR, Lee LM, Horan JM, et al. Guidelines Working Group Centers for Disease Control and Prevention (CDC). Updated guidelines for evaluating public health surveillance systems: recommendations from the Guidelines Working Group. MMWR Recomm Rep 2001;50(RR-13):1-35; quiz CE1-7.

13. Galiwango RM, Musoke R, Lubyayi L, et al. Evaluation of current rapid HIV test algorithms in Rakai, Uganda. $J$ Virol Methods 2013;192:25-7.

14. Kroidl I, Clowes $P$, Mwalongo W, et al. Low specificity of determine HIV1/2 RDT using whole blood in south west Tanzania. PLoS ONE 2012;7:e39529.

15. TheEMIS Network. The European Men-Who-Have-Sex-With-Men Internet Survey. Findings from 38 countries. Stockholm: European Center for Disease Prevention and Control, 2013.

16. Dias S, Mendão L, Gama A, et al. How to access vulnerable and hard-to-reach populations? Methodological challenges in HIV and STIs epidemiological and behavioural research with sex workers [abstract]. Eur J Epidemiol 2012(27):S1-S197.

17. ACS. The Amsterdam Cohort Studies on HIV infection and AIDS-a summary of the results 2001-2009, 2009.

18. Detels R, Jacobson L, Margolick J, et al. The multicenter AIDS Cohort Study, 1983 to... Public Health 2012;126:196-8.

19. Dufour A, Alary M, Otis J, et al. Risk behaviours and HIV infection among men having sexual relations with men: baseline characteristics of participants in the Omega Cohort Study, Montreal, Quebec, Canada. Can J Public Health 2000;91:345-9.

20. Jin F, Prestage GP, McDonald A, et al. Trend in HIV incidence in a cohort of homosexual men in Sydney: data from the Health in Men Study. Sex Health 2008;5:109-12.

21. Ferrer L EA, Ditzel E, Loureiro E, et al. High incidence among MSM in Barcelona, Catalonia: the ITACA Cohort. [abstract]. In: Presented at: Men M, Sex and HIV (FEMP 2011): the Future of European Prevention among MSM ed. Estocolm, 10-11 Nov. 2011.

22. Elford J, Jeannin A, Spencer B, et al. HIV and STI behavioural surveillance among men who have sex with men in Europe. Euro Surveill 2009;14:pii=19414. http://www.eurosurveillance.org/ ViewArticle.aspx?Articleld $=19414$

23. Lorenc T, Marrero-Guillamon I, Llewellyn A, et al. HIV testing among men who have sex with men (MSM): systematic review of qualitative evidence. Health Educ Res 2011;26:834-46.

24. Medley A, Kennedy C, O'Reilly K, et al. Effectiveness of peer education interventions for HIV prevention in developing countries: a systematic review and meta-analysis. AIDS Educ Prev 2009;21:181-206.

25. Meulbroek M, Ditzel E, Saz J, et al. BCN Checkpoint, a community-based centre for men who have sex with men in Barcelona, Catalonia, Spain, shows high efficiency in HIV detection and linkage to care. HIV Med 2013;14(Suppl 3):25-8.

26. Qvist T, Cowan SA, Graugaard C, et al. High linkage to care in a community-based rapid HIV testing and counseling project among men who have sex with men in Copenhagen. Sex Transm Dis 2014:41:209-14.

27. Ferreira PM, Cabral MV. Sexualidades em Portugal: Comportamentos e Riscos. Lisboa: Editorial Bizâncio, 2010.

28. Marcus U, Hickson F, Weatherburn P, et al. Estimating the size of the MSM populations for 38 European countries by calculating the survey-surveillance discrepancies (SSD) between self-reported new HIV diagnoses from the European MSM internet survey (EMIS) and surveillance-reported HIV diagnoses among MSM in 2009. BMC Public Health 2013;13:919.

29. Deblonde J, Hamers FF, Callens S, et al. HIV testing practices as reported by HIV-infected patients in four European countries. AIDS Care 2014;26:487-96.

30. Matkovic Puljic V, Kosanovic Licina ML, Kavic M, et al. Repeat HIV testing at voluntary testing and counseling centers in Croatia: successful HIV prevention or failure to modify risk behaviors? PLoS ONE 2014;9:e93734.

31. McCambridge J, Witton J, Elbourne DR. Systematic review of the Hawthorne effect: new concepts are needed to study research participation effects. J Clin Epidemiol 2014;67:267-77. 